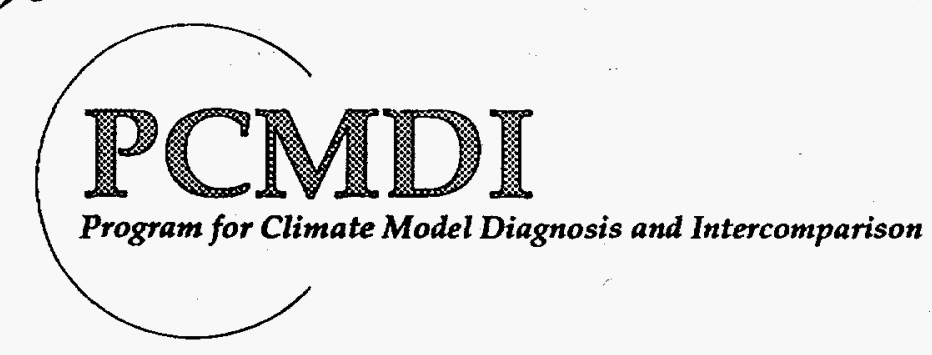

RECEIVED

OCT 271995

PCMDI Report No. 27

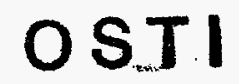

\title{
A SEARCH FOR HUMAN INFLUENCES ON THE THERMAL STRUCTURE OF THE ATMOSPHERE
}

by

B.D. Santer, K.E. Taylor, ${ }^{1,2}$ T.M.L. Wigley, P.D. Jones ${ }^{4}$, D.J. Karoly5, J.F.B. Mitchell, A.H. Oort', J.E. Penner ${ }^{2}$, V. Ramaswamy ${ }^{7}$, M.D. Schwarzkopf ${ }^{7}$, R.J. Stouffer ${ }^{7}$ and $\mathrm{S}$. Tett ${ }^{6}$

Program for Climate Model Diagnosis and Intercomparison

Lawrence Livermore National Laboratory, Livermore, CA, USA

${ }^{2}$ Global Climate Research Division

Lawrence Livermore National Laboratory

Livermore, CA 94551

$\mathbf{3}_{\text {National Center for Atmospheric Research }}$

Boulder, CO 80307-3000

${ }^{4}$ Climatic Research Unit

University of East Anglia

Norwich, NR4 7TJ

${ }^{5}$ Cooperative Research Centre for Southern Hemisphere Meteorology

Monash University

Clayton VIC 3168 Australia

${ }^{6}$ Hadley Centre for Climate Prediction and Research

Meteorological Office,

Bracknell RG12 2SY, U.K.

7NOAA/Geophysical Fluid Dynamics Laboratory, P.O. Box 308, Princeton University,

Princeton, NJ 08542

August 1995

MASTER

PROGRAM FOR CLIMATE MODEL DIAGNOSIS AND INTERCOMPARISON UNIVERSITY OF CALIFORNIA, LAWRENCE LIVERMORE NATIONAL LABORATORY LIVERMORE, CA 94550 


\section{DISCLAIMER}

This document was prepared as an account of work sponsored by an agency of the United States Government. Neither the United States Government nor the University of California nor any of their employees, makes any warranty, express or implied, or assumes any legal liability or - responsibility for the accuracy, completeness, or usefulness of any information, apparatus, product, or process disclosed, or represents that its use would not infringe privately owned rights. Reference herein to any specific commercial products, process, or service by trade name, trademark, manufacturer, or otherwise, does not necessarily constitute or imply its endorsement, recommendation, or favoring by the United States Government or the University of California. The views and opinions of authors expressed herein do not necessarily state or reflect those of the United States Government or the University of California, and shall not be used for advertising or product endorsement purposes.

This is an informal report intended primarily for internal or limited external distribution. The opinions and conclusions stated are those of the author and may or may not be those of the Laboratory.

This report has been repoduced directly from the best available copy.

Available to DOE and DOE contractors from the Office of Scientific and Technical Information

P.O. Box 62, Oak Ridge, TN 37831

Prices available from (615) 576-8401, FTS 626-8401

Available to the public from the

National Technical Information Service

U.S. Department of Commerce

5285 Port Royal Rd.,

Springfield, VA 22161 


\section{DISCLAIMER}

Portions of this document may be illegible in electronic image products. Images are produced from the best available original document. 


\title{
A Search for Human Influences on the Thermal Structure of the Atmosphere
}

\author{
B.D. Santer ${ }^{1}$, K.E. Taylor ${ }^{1,2}$, T.M.L. Wigley ${ }^{3}$, P.D. Jones ${ }^{4}$, D.J. Karoly ${ }^{5}$, \\ J.F.B. Mitchell ${ }^{6}$, A.H. Oort ${ }^{7}$, J.E. Penner ${ }^{2}$, V. Ramaswamy ${ }^{7}$, M.D. \\ Schwarzkopf $^{7}$, R.J. Stouffer ${ }^{7}$ and S. Tett ${ }^{6}$
}

${ }^{1}$ Program for Climate Model Diagnosis and Intercomparison, Lawrence Livermore National Laboratory, Livermore, CA 94550, U.S.A.

${ }^{2}$ Global Climate Research Division, Lawrence Livermore National Laboratory, Livermore, CA 94550, U.S.A.

${ }^{3}$ National Center for Atmospheric Research, Boulder, CO 80307-3000, U.S.A.

${ }^{4}$ Climatic Research Unit, University of East Anglia, Norwich, NR4 7TJ, U.K.

${ }^{5}$ Cooperative Research Centre for Southern Hemisphere Meteorology, Monash University, Clayton VIC 3168, Australia

${ }^{6}$ Hadley Centre for Climate Prediction and Research, Meteorological Office, Bracknell RG12 2SY, U.K.

${ }^{7}$ NOAA/Geophysical Fluid Dynamics Laboratory, P.O. Box 308, Princeton University, Princeton, NJ 08542

August 28, 1995

Corresponding author's address:

Dr. Benjamin D. Santer

Program for Climate Model Diagnosis and Intercomparison

Lawrence Livermore National Laboratory

P.O. Box 808, Mail Stop L-264

Livermore, CA 94550, U.S.A.

FAX: (510) 422-7675

TEL: (510) 423-4249

email: bsanter@rainbow.llnl.gov 
SEVERAL recent studies have compared observed changes in nearsurface temperature with patterns of temperature change predicted by climate models in response to combined forcing by carbon dioxide and anthropogenic sulphate aerosols ${ }^{1-3}$. These results suggest that a combined $\mathrm{CO}_{2}$ +sulphate aerosol signal is easier to identify in the observations than a pattern of temperature change due to $\mathrm{CO}_{2}$ alone. Here we extend this work to a comparison of modelled and observed patterns of vertical temperature change in the atmosphere. Results show that the observed and model-predicted changes in the mid- to low troposphere are in better accord with greenhouse warming predictions when the likely effects of anthropogenic sulphate aerosols and stratospheric ozone reduction are incorporated in model calculations, and that the level of agreement increases with time. This improved correspondence is primarily due to hemisphericscale temperature contrasts (reduced tropospheric warming in the Northern Hemisphere). If current model-based estimates of natural internal variability are realistic, it is likely that the level of time-increasing similarity between modelled and predicted patterns of vertical temperature change is partially due to human activities.

Changes in the vertical structure of atmospheric temperature have been proposed as a possible "fingerprint" of greenhouse-gas-induced climate change ${ }^{4-8}$. Until recently, most of our information about the structure of such a fingerprint has been derived from equilibrium $\mathrm{CO}_{2}$ doubling experiments performed with atmospheric General Circulation Models (AGCMs) coupled to mixed-layer oceans ${ }^{9,10}$. These experiments yielded a fingerprint pattern characterized by stratospheric cooling, tropospheric warming, a warming maximum in the tropical upper troposphere, and (for annual mean zonally-averaged changes) an approximate hemispheric symmetry of the temperature response (see Fig. 1a).

One recent study ${ }^{11}$ has compared such model-predicted patterns of temperature change with observed latitude-height temperature-change profiles. The latter were 
obtained from the radiosonde analyses of Oort, and span the period $1963-87^{12,13}$. The conclusion reached by this work was that the observed data showed an increasing expression of the equilibrium temperature-change signal predicted by two different AGCMs in response to $\mathrm{CO}_{2}$ doubling. This time-increasing similarity was judged to be significant, and it was further concluded that the individual pattern signatures of El Niño-Southern Oscillation (ENSO) events and stratospheric ozone reduction were spatially dissimilar to the searched-for $\mathrm{CO}_{2}$ fingerprint.

Although suggestive of a causal relationship between increasing levels of atmospheric $\mathrm{CO}_{2}$ and the vertical structure of atmospheric temperature changes, this investigation did not claim attribution of all or even part of the observed changes to the specific cause of changes in $\mathrm{CO}_{2}$. The principal uncertainties were related to the quality and short record length of the radiosonde data, the lack of a dynamic ocean in the model experiments, the neglect of other anthropogenic forcings (such as changes in sulphate aerosol loadings) and concerns regarding the estimation of significance by resampling of the observed data ${ }^{11,14}$. One further concern was whether natural climatic variability could mimic the model-predicted greenhouse fingerprint, as preliminary analyses of observations and model control runs had suggested ${ }^{15-18}$ : All of these factors hampered more confident statements regarding detection of a significant change, and attribution of (some fraction of) that change to increasing $\mathrm{CO}_{2}$.

Our investigation differs from this earlier work in three ways. First, we examine the relative detectability of vertical temperature-change signals from recent experiments with individual and combined changes in atmospheric $\mathrm{CO}_{2}$ and anthropogenic sulphate aerosols ${ }^{19}$. Second, we consider how a combined $\mathrm{CO}_{2}+\mathrm{SO}_{4}$ vertical temperature-change signal might be modified by observed changes in stratospheric ozone. It is highly likely that recent reductions in stratospheric ozone are in part attributable to industrial production of halocarbons ${ }^{20}$. These changes may have a complex signature in the thermal structure of the atmosphere, varying as a function of latitude, altitude and season ${ }^{21}$. One recent study that has forced an atmospheric GCM by changes in both $\mathrm{CO}_{2}$ and stratospheric ozone has shown that the inclusion 
of ozone effects improves model agreement with the Oort temperature data (at least in global-mean terms), particularly in the upper troposphere ${ }^{22}$. At present, no atmospheric GCM has been forced by combined changes in $\mathrm{CO}_{2}$, anthropogenic sulphate aerosols and stratospheric ozone. Pending the availability of results from such an experiment, we perform a simple sensitivity study by linearly combining results from ozone-only ${ }^{23}$ and $\mathrm{CO}_{2}+\mathrm{SO}_{4}{ }^{19}$ model studies.

Third, we use information from two long model control integrations with no changes in greenhouse gases, sulphate aerosols or ozone to assess the significance of trends in model-versus-observed pattern similarity. Such integrations provide estimates of the magnitude and patterns of multi-decadal internally-generated natural climate variability - information that is impossible to obtain from the short $(\leq 40$ year) radiosonde temperature record.

\section{Model and Observed Data}

The $\mathrm{CO}_{2}$-only and $\mathrm{CO}_{2}+\mathrm{SO}_{4}$ vertical temperature-change signals that we attempt to detect in the observed data were taken from experiments performed by Taylor and Penner ${ }^{19}$ (henceforth TP) with the GRANTOUR tropospheric chemistry model ${ }^{24}$ coupled to the Livermore version of the National Center for Atmospheric Research Community Climate Model $^{25}$ (NCAR CCM-1). The AGCM was coupled to a 50meter mixed-layer ocean with prescribed meridional heat transport. GRANTOUR is a Lagrangian trace species model that simulates the transport, transformation and removal of various sulphur species ${ }^{26}$. The coupled chemistry-climate model considers only the direct radiative effects of sulphate aerosols (reflection of incident solar radiation). It does not treat indirect aerosol effects on climate due to changes in cloud microphysical properties ${ }^{27-29}$ or the radiative effects of carbonaceous and mineral aerosols from biomass burning and land surface modification ${ }^{30,31}$.

In addition to a control run with nominal pre-industrial $\mathrm{CO}_{2}(270 \mathrm{ppmv})$ and no 
anthropogenic sulphur emissions, three perturbation experiments were performed: a sulphate-only experiment $(S)$ with near-present-day anthropogenic sulphur emissions, a $\mathrm{CO}_{2}$-only experiment $(\mathrm{C})$ with near-present-day $\mathrm{CO}_{2}$ levels (345 ppmv), and an experiment with combined present-day $\mathrm{CO}_{2}$ levels and anthropogenic sulphur emissions $(\mathrm{SC})^{19}$. All integrations were at least 30 years in duration, and temperature-change signals were computed using averages over the last 20 years of the control run and each perturbation experiment. The signals therefore represent equilibrium changes between present-day and preindustrial conditions.

To study how a reduction in stratospheric $\mathrm{O}_{3}$ might modify the $\mathrm{SC}$ signal pattern, we use data from an experiment performed by Ramaswamy et al. with the GFDL SKYHI atmospheric $\mathrm{GCM}^{23}$. The model was forced with observed monthly-mean zonal average changes in stratospheric ozone over the period 1979-1990, and was run with fixed cloud distributions in the troposphere and sea-surface temperature prescribed according to climatology. An idealized vertical structure of ozone losses was imposed, with constant percentage reductions in an atmospheric region extending from the tropopause to roughly $7 \mathrm{~km}$ above ${ }^{23}$. The model-predicted spatio-temporal signal in the lower stratosphere is generally in good accord with available satellitebased temperature measurements ${ }^{23}$.

The Oort radiosonde analyses of temperature were available as anomalies (for DJF, JJA, and annually-averaged data) relative to a reference period of 1963-73, and spanned the period 1963-87 12,13 . Observed data are in the form of zonal averages for seven atmospheric levels $(850,700,500,300,200,100$, and $50 \mathrm{hPa})$. The principal uncertainties in this data set have been described previously ${ }^{11,13}$. The most serious include the existence of time-varying instrumental biases and inadequate spatial coverage, particularly over the Southern Ocean. Preliminary comparisons between the Oort data and satellite-derived estimates of vertical temperature changes indicate that the two data sets are in good agreement over the period of overlap (1979-1990), at least in global- ${ }^{32}$ and hemispheric-mean terms ${ }^{13}$. The largest differences are in the tropics between ca. $10^{\circ} \mathrm{N}-10^{\circ} \mathrm{S}^{32}$. 
Note that the amplitudes of observed changes and the $\mathrm{SC}$ and $\mathrm{O}_{3}$ responses are not directly comparable, since all three represent temperature responses to radiative forcing changes over different periods - i.e., over the 25 years from 1963-87 in the case of the Oort data, and over roughly the last 10 and 100 years in the case of the Ramaswamy et al. and TP integrations (respectively). If the radiative forcing histories and lags between forcing and response were known exactly for $\mathrm{O}_{3}, \mathrm{CO}_{2}$ and sulphate aerosols (direct effects), it would be possible to make a more meaningful comparison of the amplitudes of observed and modelled vertical temperature changes by scaling according to differences in overall forcing. Large forcing uncertainties, particularly for sulphate aerosol direct effects, make such scaling exercises very difficult. This issue is important in the linear superposition of $\mathrm{O}_{3}$ and SC signals, and we return to it later in our statistical analysis of model-versus-observed pattern similarity.

\section{Patterns of Vertical Temperature Change}

Modelled and observed patterns of annual-mean zonal-mean temperature change ('signals') as a function of latitude and height are shown in Fig. 1. The TP $\mathrm{C}$ signal (Fig. 1a) is in accord with the signals yielded in $\mathrm{CO}_{2}$ doubling experiments performed with other models using similar AGCM/mixed-layer ocean configurations ${ }^{9-11}$. It shows stratospheric cooling and tropospheric warming, with maximum warming in the tropical upper troposphere. Temperature changes are hemispherically-symmetric. In contrast, both the S (Fig. 1b) and SC (Fig. 1c) signals are characterized by a hemispherically-asymmetric response, with (respectively) increased cooling and reduced warming in the Northern Hemisphere, where anthropogenic sulphate aerosol forcing is largest ${ }^{19,33}$. Similar patterns occur for DJF and JJA (not shown). Stratospheric cooling and tropospheric warming are prominent features of both the $\mathrm{C}$ and SC signals, and the average height of the transition between cooling and warming (ca. $100 \mathrm{hPa}$ ) is similar in each case. 
Vertical temperature changes from the Ramaswamy et al. stratospheric $\mathrm{O}_{3}$ reduction experiment are characterized by stratospheric cooling, with maximum cooling (in excess of $-1^{\circ} \mathrm{C}$ ) at high latitudes in both hemispheres (Fig. 1d). Due to dynamical effects, cooling occurs throughout the lower stratosphere, even at low latitudes where the imposed ozone changes are negligible ${ }^{23}$. The $\mathrm{O}_{3}$-only response is not hemispherically-symmetric: stratospheric cooling that is statistically significant ${ }^{23}$ occurs over a wider area in the mid- to high-latitude Northern Hemisphere than in the Southern Hemisphere. In the upper troposphere, cooling extends further equatorward in the Northern Hemisphere. This is primarily due to a hemispheric asymmetry in the observed ozone changes. Note that some of the model-observed temperature differences above $100 \mathrm{hPa}$, such as the warming above ca. $70 \mathrm{hPa}$ polewards of $45^{\circ} \mathrm{S}$, are likely related to the idealized altitudinal profile of ozone loss ${ }^{34}$. Other differences between Figs. 1d and If are related to the different time periods considered in the model experiment and in the observations.

As a sensitivity study, we form two linear combinations of the $\mathrm{O}_{3}$ and $\mathrm{CO}_{2}+\mathrm{SO}_{4}$ temperature-change signals from the Ramaswamy et al. and TP experiments. COMB1 is the unweighted linear combination of the $\mathrm{SC}$ and $\mathrm{O}_{3}$ signals (Fig. 1e). COMB2 (not shown) illustrates the effect of the previously-discussed uncertainties in the relative amplitudes of the $\mathrm{SC}$ and $\mathrm{O}_{3}$ signal components by halving the amplitude of the $\mathrm{SC}$ signal (i.e., $\mathrm{COMB} 2=\frac{1}{2} \mathrm{SC}+\mathrm{O}_{3}$ ).

For either COMB1 or COMB2 to be a realistic estimate of the response to combined $\mathrm{CO}_{2}+\mathrm{SO}_{4}+\mathrm{O}_{3}$ forcing requires not only that the relative weights of the individual forcings are accurate, but also that the climate system responds linearly to small perturbations about the mean state ${ }^{35}$. We have tested this linear superposition assumption and found it to be valid for the $\mathrm{C}$ and $\mathrm{S}$ signals. This was done by comparing the response to combined forcing in the $\mathrm{SC}$ experiment with the linear combination of $\mathrm{C}$ and $\mathrm{S}$ responses. It is not possible at present to test whether $\mathrm{O}_{3}$ effects can also be included in this way, since suitable model studies with individual and combined forcing are not available. The best available information suggests that 
a linear combination of $\mathrm{O}_{3}$ and $\mathrm{SC}$ effects is reasonable, since the stratospheric temperature response to $\mathrm{O}_{3}$ changes overwhelms the stratospheric response to all other anthropogenic forcings ${ }^{23}$.

The incorporation of ozone effects does not modify the SC response pattern as markedly as the inclusion of aerosol effects modified the C pattern. Stratospheric cooling is intensified by the incorporation of $\mathrm{O}_{3}$ results, as is the interhemispheric asymmetry. The height of the transition between stratospheric cooling and tropospheric warming is reduced relative to the SC case (c.f. Figs. 1c and 1e), but is still roughly $50 \mathrm{hPa}$ higher than in observations (Fig. 1f). Note that there are uncertainties relating to observed $\mathrm{O}_{3}$ losses and thus the simulated temperature changes in the vicinity of the tropopause $\mathrm{e}^{23,34}$. These uncertainties have an influence on the transition height between stratospheric cooling and tropospheric warming in Fig. 1e. The coarse vertical resolution of the Oort data also hampers a more accurate determination of model-versus-observed discrepancies in transition height.

Fig. If shows observed temperature changes, expressed as linear trends over the 25-year period 1963-87. The observed changes show evidence of reduced warming in the Northern Hemisphere between 850-300 hPa, a feature that has been documented in previous investigations ${ }^{7,8,13}$ and is also prominent in seasonally-averaged data ${ }^{36}$. It is visually obvious that the observed change pattern is in better accord with the $\mathrm{SC}$ and COMB1 signals than with the $\mathrm{C}$ signal. Stratospheric cooling and tropospheric warming are clearly features of the observations as well as the model C, SC and COMB1 experiments, although the observed cooling extends lower in the atmosphere (to roughly $200 \mathrm{hPa}$ in the tropics and $500-700 \mathrm{hPa}$ from $45^{\circ} \mathrm{N}-90^{\circ} \mathrm{N}$ ).

Although the model signals and observations in Fig. 1 represent changes over different time periods, it is nonetheless instructive to compare their global-mean profiles of annually-averaged temperature change (Fig. 2). This clearly illustrates that incorporating the effect of stratospheric $\mathrm{O}_{3}$ reduction in COMB1 produces a more realistic profile and transition height between stratospheric cooling and tropospheric warming 
than in either $\mathrm{C}$ or $\mathrm{SC}^{22}$. Results for COMB2 (not shown) are in closest agreement with the observed profile. Note that in global mean terms there is virtually no impact of stratospheric $\mathrm{O}_{3}$ reduction below ca. $350 \mathrm{hPa}$ (compare $\mathrm{SC}$ and COMB1 results). The result for $\mathrm{S}$ is not the inverse of $\mathrm{C}$, and shows the large radiative effect of $\mathrm{CO}_{2}$ above ca. $70 \mathrm{hPa}$.

\section{Pattern Similarity}

The method we employ to compare model and observed vertical temperature-change patterns uses a so-called 'centered' correlation statistic, $R(t)^{1,37}$, in which the anomaly fields being compared are centered about the spatial means of each field:

$$
R(t)=\left[\sum_{x=1}^{n}(\Delta D(x, t)-\widehat{\triangle D}(t))(\Delta M(x)-\widehat{\Delta M})\right] /\left[n s_{D}(t) s_{M}\right]
$$

$\Delta D$ and $\triangle M$ denote temperature-change fields for observed Data and Model output, respectively, and the indices $x$ and $t$ are discrete variables running over space $(x=1, \ldots n$, the combined latitude-height dimension of the Oort data) and time ( $t=1963, \ldots 1987$, the years covered by the Oort data set). Observed changes are expressed as anomalies relative to the average over 1963-73, and model changes represent the difference between time-averaged states in perturbation and control experiments. The - indicates a spatial average. The observed spatial variance $s_{D}^{2}(t)$ is given by

$$
s_{D}^{2}(t)=\sum_{x=1}^{n}[\Delta D(x, t)-\widehat{\Delta D}(t)]^{2} /(n-1)
$$

with the model spatial variance $s_{M}^{2}$ defined similarly. Observed data were smoothed with a 13-term Gaussian filter to suppress variability on time scales shorter than a decade (e.g., associated with ENSO events and the quasi-biennial oscillation) ${ }^{1}$ All 
pattern correlations were computed using pressure- and area-weighted data.

It is evident from (1) that the observed data have a time-dependence while the model signals do not. If the observed time-varying patterns of temperature change are becoming increasingly similar to the (time-invariant) model-predicted equilibrium responses shown in Figs. 1a-e, the $R(t)$ statistic will show a sustained positive trend ${ }^{38}$. This trend is unlikely to be linear and monotonic, since the observations reflect a response not only to the change with time in the anthropogenic forcing specified in the model experiment, but also a response to changes over space and time in other human-induced and natural forcings, and additionally incorporate some component of 'unforced' natural variability. There are two main issues of interest: whether trends in $R(t)$ are very different for different model signals, and whether trends in $R(t)$ could be due to internal natural variability alone.

The premise underlying the use of a centered correlation for attribution is that different "causes" (forcing mechanisms) have different response patterns. If one can demonstrate time-increasing correspondence between the observations and a modelpredicted pattern of change, and show that correspondence exists at hemispheric or smaller spatial scales - not only at the surface, but also in the full three-dimensional structure of the atmosphere - then it is unlikely that forcing mechanisms other than the ones being considered could exactly match the predicted response pattern.

Fig. 3a shows $R(t)$ values for signals from the $\mathrm{C}$ and $\mathrm{SC}$ experiments and from the COMB1 and COMB2 sensitivity studies. Pattern correlations were computed over the full vertical domain of the Oort data $(50$ to $850 \mathrm{hPa}$ ). $R(t)$ trends for all four signal patterns are positive over the 25-year period, indicating an increasing expression of the model-predicted patterns in the observed seasonally-and annually-averaged data. Similarities in the behaviour of the $R(t)$ time series are due to the large vertical temperature gradient common to the four signal patterns (see Figs. 1a,c,e; COMB2 results not shown). This gradient dominates the patterns being compared, and overwhelms the 'benefit' of reducing the height of stratospheric cooling/tropospheric warming 
transition level in COMB1 and COMB2. Note also that differences in the magnitudes of the $\mathrm{C}, \mathrm{SC}, \mathrm{COMB} 1$ and COMB2 vertical gradients are scaled by the model spatial variances, $s_{M}^{2}$. Together these factors explain why differences are relatively small when $R(t)$ is computed over the full vertical domain covered by the Oort data.

To better resolve the effects of different hemispheric asymmetry in the various signals, we restricted the domain of the model-versus-observed pattern comparison to the low- to mid-troposphere $(500 \mathrm{hPa}$ to $850 \mathrm{hPa})$, and then recomputed $R(t)$. Exclusion of stratospheric changes reduces the large vertical temperature gradient, and focusses attention on the smaller-amplitude interhemispheric structure of the signals. $R(t)$ time series now show overall positive trends for the SC, COMB1 and COMB2 signals, but little or no trend for the C signal (Fig. 3b). Absolute values of $R(t)$ are generally slightly higher for COMB2 and COMB1 than for the SC signal. We conclude from this that observed changes in the low- to mid-troposphere (which may be more reliable than changes in the stratosphere ${ }^{39}$ ) are in better agreement in all seasons with the COMB1, COMB2, and SC signals than with the $\mathrm{C}$ signal. The primary reason for this discrimination is the interhemispheric asymmetry (reduced warming in the Northern Hemisphere in DJF, JJA and annually-averaged data) common to the observations and the SC, COMB1 and COMB2 signals. In the model signals, this asymmetry is largely due to incorporation of sulphate aerosol effects, although ozone changes may slightly enhance the interhemispheric temperature contrast.

\section{Trend Significance}

Are the positive $R(t)$ trends in Figs. 3a,b unusually large relative to the trends we might expect in the absence of any anthropogenic forcing - i.e., due to internallygenerated variability of the coupled atmosphere-ocean system? To address the issue of trend significance, we use natural variability noise information from two separate sources: a 310-year control experiment performed with the Hadley Centre coupled 
atmosphere-ocean GCM (CGCM) ${ }^{2}$, and a 1,000-year control run with the GFDL $\mathrm{CGCM}^{40}$. Both integrations were run with fixed atmospheric $\mathrm{CO}_{2}$ and $\mathrm{O}_{3}$ and with no forcing by anthropogenic sulphate aerosols. They also lack any changes in solar variability or in the atmospheric loading of volcanic aerosols.

The variability of near-surface temperature changes in both integrations has been documented previously and compared with observations ${ }^{40-42}$. On timescales of 10-30 years (appropriate to the length of the radiosonde record) there is good agreement between the GFDL and Hadley Centre spectra and the observed spectrum for globalmean annually-averaged near-surface temperature ${ }^{40,43}$. A preliminary comparison of model and observed patterns of variability suggests that the typical spatial and temporal coherence of simulated anomaly patterns is similar to that of the observations on timescales of 5 to 10 years, although there are differences on shorter timescales.

Rigorous validation of the model-estimated internal variability of vertical temperature changes is problematic: we do not have a suitable 'standard' with which to compare due to the difficulty of separating internal variability from anthropogenic effects in the observations. For the purposes of this investigation we assume that the Hadley Centre and GFDL CGCMs provide credible estimates of the magnitude and patterns of internal natural variability on timescales ranging from 10 to 25 years. Our use of noise information from two separate control runs provides some indication of the robustness of our significance estimates to uncertainties in the model-estimated noise.

The significance testing procedure follows Santer et al. ${ }^{1}$. The C, SC, COMB1, and COMB2 signal patterns are first correlated with the vertical temperature changes simulated in the CGCM control runs. The resulting time series provide information on the behaviour of the $R(t)$ statistic in the absence of external forcing. By fitting 10-, 15-, and 25-year linear trends to overlapping chunks of the 'natural' $R(t)$ time series, we generate sampling distributions of unforced $R(t)$ trends and then determine whether the trends in $R(t)$ in Figs. $3 \mathrm{a}$ and $\mathrm{b}$ over the last 10 - to 25 years are unusual 
occurrences (Fig. 4).

If model signal patterns and observed data are compared over a vertical domain from 50 to $850 \mathrm{hPa}$, the 25-year $R(t)$ trends for all signals (C, SC, COMB1 and COMB2) and in all seasons examined here are significantly different from unforced trends (Table 1). This result indicates that the observed change in the vertical temperature gradient over 1963-87 is large relative to the typical 25-year changes in the model control runs. The 15-year $R(t)$ trends are also highly significant for all signals, but in DJF only. Only three of the 10 -year $R(t)$ trends achieve significance at the $5 \%$ level or better.

Restricting the comparison of signals, observed changes and noise patterns to 500 to $850 \mathrm{hPa}$ yields a clear discrimination between the $\mathrm{C}$ signal and the SC, COMB1, and COMB2 signals: in DJF and in the annually-averaged data, the 25-year $R(t)$ signal trends are significant for the three cases with combined forcing, but not for the $\mathrm{CO}_{2}$-only signal. As noted above, this result largely reflects the hemispheric asymmetry of warming in the observations and the SC, COMB1, and COMB2 signals, with reduced warming in the Northern Hemisphere in all seasons. Although the 25year $R(t)$ trends in JJA are not significant at the $5 \%$ level or better, there is still a marked difference between the $\mathrm{CO}_{2}$-only and combined forcing results. Significance levels are relatively insensitive to the choice of CGCM control run used to estimate natural internal variability.

\section{Conclusions}

The results obtained here are in accord with the conclusions of Santer et al. ${ }^{1}$, who found that observed near-surface temperature changes were in closer agreement with the combined $\mathrm{SC}$ signal than with the $\mathrm{C}$ signal. In the present study, the closer accord between observed vertical temperature changes and the SC signal is due to the fact that both show clear evidence of interhemispheric asymmetry, with reduced warming 
in the Northern Hemisphere extending throughout the low- to mid-troposphere. This asymmetry is evident in all seasons examined here. If the estimates of internallygenerated natural variability used here are realistic, we can be confident that the level of time-increasing agreement between observed changes over 1963-87 and model predictions for a combined SC signal is unlikely to have occurred by natural internal fluctuations alone.

In the absence of relevant experiments with simultaneous changes in $\mathrm{CO}_{2}, \mathrm{O}_{3}$, and anthropogenic sulphate aerosols, we have linearly combined the results of separate $\mathrm{O}_{3}$-reduction and $\mathrm{SC}$ experiments in order to assess the possible effects of ozone changes on an SC signal. This should be regarded as a sensitivity study only, and does not obviate the need for more relevant experiments. Nevertheless, we note that the pattern correspondence between observed temperature changes and model SC predictions in the mid- to low-troposphere is improved by incorporating the possible temperature effects of stratospheric ozone reduction. The implication of the recent work by Hansen et al. ${ }^{22}$, Ramaswamy et al. ${ }^{23}$ and the present study is that climatechange detection investigations that ignore possible ozone effects are likely to be searching for a sub-optimal signal (at least in terms of vertical temperature changes).

There are a large number of uncertainties in our investigation, and indeed in all climate-change detection studies that rely on model estimates of an expected anthropogenic signal and natural variability noise $1,2,3,44,45$. The uncertainties in the signals used here are manifold. The most important of these relate to the relative magnitudes of the various forcing components and the neglect of other (possibly significant) anthropogenic forcings - e.g., due to sulphate aerosol indirect effects, other anthropogenic aerosols ${ }^{30,31,46}$, and changes in non- $\mathrm{CO}_{2}$ greenhouse gases and tropospheric ozone.

Dynamic ocean effects are also likely to be important in defining the signal for any given forcing. Transient $\mathrm{CO}_{2}$-only experiments with fully-coupled CGCMs yield hemispheric asymmetry in the opposite sense to that found in the TP SC experiment, 
with reduced warming in the Southern Hemisphere. This is due in part to penetrative mixing and increased heat uptake by the intermediate and deep ocean. Thus we could expect the incorporation of full ocean dynamics to modify the SC signal patterns used here, which were obtained from an AGCM coupled to a mixed-layer ocean. However, the best information that we have from a transient model simulation with full ocean dynamics and changes in both $\mathrm{CO}_{2}$ and sulphate aerosols indicates that the hemispheric asymmetry found in the TP SC signal is reduced and somewhat noisier, but not reversed ${ }^{47}$.

An additional uncertainty pertains to the realism of the CGCM-derived natural variability noise ${ }^{48}$. This was used here to assess the likelihood that natural climate fluctuations could have fortuitously resulted in large trends in our pattern similarity statistic. The model noise estimates reflect natural variations internal to the climate system, and do not incorporate variability due to changes in solar luminosity or the volcanic aerosol loading of the atmosphere. The validity of these model-based estimates of natural internal variability - in terms of pattern, amplitude, and timescale - is largely unknown on timescales longer than 10 years. Hence the significance levels estimated here are highly uncertain.

Could volcanic effects explain part or even all of the observed changes in the thermal structure of the atmosphere? It is difficult to answer this question without a longer observed record and more relevant model experiments. There is little evidence that the observed pattern of stratospheric cooling and tropospheric warming is due to volcanic effects, which tend to warm the stratosphere and cool the surface $e^{49,18}$. It is conceivable that volcanic effects could have contributed towards the observed interhemispheric asymmetry in tropospheric temperature changes over 1963 to 1987 , since the eruption of Mt. Agung in 1963 had a larger cooling effect in the Southern Hemisphere, while the climatic response to the El Chichón eruption in 1982 was primarily in the Northern Hemisphere ${ }^{50}$. We note, however, that the observed hemispheric temperature asymmetry in the $850-300 \mathrm{hPa}$ layer is also evident in a radiosonde data set commencing in 1958 and predating any Agung effect by five years ${ }^{36}$. 
We have attempted to minimize short-timescale volcanic effects by filtering the observed data. It is clear from Fig. $3 \mathrm{~b}$, particularly in JJA and the annually-averaged data, that there is a large difference in the absolute values of the $R(t)$ results for the combined forcing and $\mathrm{CO}_{2}$-only cases. The (hemispherically-asymmetric) signals due to combined $\mathrm{CO}_{2}, \mathrm{SO}_{4}$ and $\mathrm{O}_{3}$ forcing are in better accord with the available data even during times when there has been little or no volcanic effect on climate.

These results, and those of other studies of near-surface temperature changes ${ }^{1,2,14}$ suggest that volcanic effects cannot explain all of the observed hemispheric asymmetry in tropospheric temperature changes, and that the observed changes are likely to include an anthropogenic component. Quantification of the relative magnitude of natural and human-induced climate effects is a difficult task. This will require improved histories of radiative forcing, more detailed analyses of observed data, and numerical experiments that better define an anthropogenic climate-change signal and the variability due to purely natural causes.

\section{Acknowledgments}

Work at Lawrence Livermore National Laboratory was performed under the auspices of the U.S. Dept. of Energy, Environmental Sciences Division, under contract W7405-ENG-48. Support for ST and JM was provided by the U.K. DoE under contract PECD 7/12/37. TMLW and PDJ were supported by the U.S. Dept. of Energy, Environmental Sciences Division, under grant no. DE-FG02-86ER60397. TMLW was also supported under the NOAA Climate Change, Data and Detection Program. The MECCA Program supplied some of the computer time required for the TP integrations. The authors are grateful to Alan Robock, Tom Karl, Jerry Mahlman and Suki Manabe for comments and helpful suggestions and to Lisa Corsetti for programming assistance. All color graphics were produced with software developed at the Program for Climate Model Diagnosis and Intercomparison by Dean Williams, 
Bob Mobley and Bob Drach.

\section{References}

1. Santer, B.D., Taylor, K.E., Wigley, T.M.L., Penner; J.E., Jones, P.D. \& Cubasch, U. Clim. Dyn. (in press).

2. Mitchell, J.F.B., Johns, T.C., Gregory, J.M., Tett, S.F.B. Nature 376, 501-504 (1995).

3. Hasselmann, K., Bengtsson, L., Cubasch, U., Hegerl, G.C., Rodhe, H., Roeckner, E., Storch, H.v., Voss, R. \& Waszkewitz, J. Max-Planck-Institut für Meteorologie, Report No. 168, Hamburg, Germany, 20 pp. (1995).

4. Madden, R.A. \& Ramanathan, V. Science 209, 763-768 (1980).

5. Bell, T.L. J. Geophys. Res. 87, 11,161-11,170 (1982).

6. Epstein, E.S. J. Appl. Met. 21, 1,172-1,182 (1982).

7. Karoly, D.J. Geophys. Res. Lett. 14, 1139-1141 (1987).

8. Karoly, D.J. Geophys. Res. Lett. 16, 465-468. (1989).

9. Schlesinger, M.E. \& Mitchell, J.F.B. Rev. of Geophys. 25, 760-798 (1987).

10. Mitchell, J.F.B., Manabe, S., Meleshko, V. \& Tokioka, T. in Climate Change. The IPCC Scientific Assessment (eds. Houghton, J.T., Jenkins, G.J. \& Ephraums, J.J.) (Cambridge University Press, 1990).

11. Karoly, D.J., Cohen, J.A., Meehl, G.A., Mitchell, J.F.B., Oort, A.H., Stouffer, R.J. \& Wetherald, R.T. Clim. Dyn. 10,97-105. (1994).

12. Oort, A.H. Global Atmospheric Circulation Statistics. Nat. Oceanic Atmos. Adm. Prof. Paper 14 (1983). 
13. Oort, A.H. \& Liu, H. J. Clim. 6, 292-307 (1993).

14. Karl, T.R. Nature 371, 380-381 (1994).

15. Wigley, T.M.L. \& Barnett, T.P. in Climate Change. The IPCC Scientific Assessment (eds. Houghton, J.T., Jenkins, G.J. \& Ephraums, J.J.) (Cambridge University Press, 1990).

16. Liu, Q. \& Schuurmanns, C.J.E. Geophys. Res. Lett. 17, 1085-1088 (1990).

17. Santer, B.D., Brüggemann, W., Cubasch, U., Hasselmann, K., Höck, H., Maier- Reimer, E. \& Mikolajewicz, U. Clim. Dyn. 9, 267-285 (1994).

18. Vinnikov, K. Ya., Robock, A. \& Stouffer, R.J. Nature (submitted).

19. Taylor, K.E. \& Penner, J.E. Nature 369, 734-737 (1994).

20. Prather, M., Derwent, D., Ehhalt, D., Fraser, P., Sanhueza, E. \& Zhou, X. in Climate Change 1994. Radiative Forcing of Climate Change and an Evaluation of the IPCC IS92 Emission Scenarios (eds Houghton, J.T., Meira Filho, L.G., Bruce, J., Lee, Hoesung, Callander, B.A., Haites, E., Harris, N. \& Maskell, K.) (Cambridge University Press, 1994).

21. Stolarski, R., Bojkov, R., Bishop, L., Zerefos, C., Staehelin, J. \& Zawodny, J. Science 256, 342-349 (1992).

22. Hansen, J.E., Wilson, H., Sato, M., Ruedy, R., Shah, K.P. \& Hansen, E. Clim. Change 30, 103-117 (1995).

23. Ramaswamy, V., Schwarzkopf, M.D. \& Randel, W.J. Nature (submitted).

24. Walton, J.J., MacCracken, M.C. \& Ghan, S.J. J. Geophys. Res. 93, 8339-8354 (1988).

25. Taylor, K.E. \& Ghan, S.J. J. Clim. 5, 907-919 (1992).

26. Penner, J.E., Atherton, C.A. \& Graedel, T.E. in Global Atmospheric-Biospheric Chemistry (ed Prinn, R.) (Plenum Publishing, 1994, pp. 223-248). 
27. Jones, A., Roberts, D.L. \& Slingo, A. Nature 370, 450-453 (1994).

28. Erickson, D.J., Oglesby, R.J. \& Marshall, S. Geophys. Res. Lett. 22, 2017-2020 (1995).

29. Shine, K.P., Fouquart, Y., Ramaswamy, V., Solomon, S. \& Srinivasan, J. in Climate Change 1994. Radiative Forcing of Climate Change and an Evaluation of the IPCC IS92 Emission Scenarios (eds Houghton, J.T., Meira Filho, L.G., Bruce, J., Lee, Hoesung, Callander, B.A., Haites, E., Harris, N. \& Maskell, K.) (Cambridge University Press, 1994).

30. Penner, J.E., Dickinson, R. \& O'Neill, C. Science.256, 1,432-1,434 (1992)

31. Tegen, I. \& Fung, I: J. Geophys. Res. (accepted).

32. Christy, J.R. Clim. Change (submitted).

33. Mitchell, J.F.B., Davis, R.A., Ingram, W.J. \& Senior, C.A. J. Climate (in press).

34. Mahlman, J.D., Pinto, J.P. \& Umscheid, L.J. J. Atmos. Sci. 51, 489-508 (1994).

35. Ramaswamy, V. \& Chen, C.-T. Nature (submitted).

36: Angell, J.K. . J. Climate 1, 1,296-1,313 (1988).

37. Santer, B.D., Wigley, T.M.L. \& Jones, P.D. Clim. Dyn. 8, 265-276 (1993).

38. Barnett, T.P. \& Schlesinger, M.E. J. Geophys. Res. 92, 14,772-14,780 (1987).

39. Parker, D.E. \& Cox, D.I. Int. J. Climatol. (in press).

40. Stouffer, R.J. Manabe, S. \& Vinnikov, K. Ya. Nature 367, 634-636 (1994).

41. Tett, S., Johns, T.C. \& Mitchell, J.F.B. (in preparation).

42. Manabe, S. \& Stouffer, R.J. J. Climate (accepted). 
43. Santer, B.D., Wigley, T.M.L., Barnett, T.P., Anyamba, E. in Climate Change 1995: The IPCC Scientific Assessment (in preparation).

44. Karl, T.R., Knight, R.W., Kukla, G. \& Gavin, J. in Aerosol Forcing of Climate (eds Charlson, R. \& Heintzenberg, J.) (John Wiley and Sons, 1995)

45. Hegerl, G.C., Storch, H.v., Hasselmann, K., Santer, B.D., Cubasch, U. \& Jones, P.D. Max-Planck-Institut für Meteorologie, Report No. 142, Hamburg, Germany, 59 pp. (1994).

46. Penner, J.E., Charlson, R.J., Hales, J.M., Laulainen, N.S., Leifer, R., Novakov, T., Ogren, J., Radke, L.F., Schwartz, S.E. \& Travis, L. Bull. Am. Met. Soc. 75, 375-400 (1994).

47. Tett, S. (pers. comm.)

48. Barnett, T.P., Santer, B.D., Jones, P.D., Bradley, R.S. \& Briffa, K.R. The Holocene (submitted).

49. Hansen, J.E., Wang, W.-C. \& Lacis, A.A. Science 199, 1065-1068 (1978).

50. Robock, A. \& Free, M.P. J. Geophys. Res. 100, 11,549-11,567 (1995). 


\section{Figure and Table Captions}

Figure 1: Modelled and observed zonal-mean annually-averaged changes in the thermal structure of the atmosphere. Model results in panels a-c are from experiments performed by Taylor and Penner $(\mathrm{TP})^{19}$. The equilibrium changes are for nominal 'present-day' levels of atmospheric $\mathrm{CO}_{2}$ only (C; panel a), anthropogenic sulphate aerosols only ( $\mathrm{S}$; panel b), and combined forcing by $\mathrm{CO}_{2}+$ sulphate aerosols (SC; panel c), and are referenced to a control run with preindustrial levels of $\mathrm{CO}_{2}$ and no anthropogenic sulphur emissions. The possible effects of stratospheric ozone reduction over the period 1979-90 are illustrated in a recent in an experiment by Ramaswamy et al. ${ }^{23}$ (panel d). The linear combination ('COMB1') of the $\mathrm{SC}$ and $\mathrm{O}_{3}$ signals is shown in panel e. Observed changes (panel f) are radiosonde-based temperature measurements from the data set by Oort ${ }^{12,13}$, and are expressed as total least-squares linear trends $\left({ }^{\circ} \mathrm{C}\right)$ over the 25-year period extending from May 1963 to April 88. Prior to computing linear trends the observations were filtered ${ }^{1}$ to suppress short-term variability.

Figure 2: Profiles of global-mean annually-averaged temperature change in model perturbation experiments and observations. The model and observed results are the area- and pressure-weighted global averages of the latitude-height sections presented in Fig. 1. Model and observed results represent changes over different periods of time (see Fig. 1 and text).

Figure 3: Time series of centered pattern correlations, $R(t)$, between model-predicted and observed changes in zonal-mean latitude-height profiles of atmospheric temperature. Four sets of model signal patterns are used: from the TP C and SC experiments, and from two linear combinations of the SC signal with the Ramaswamy et al. ${ }^{23} \mathrm{O}_{3}$ reduction signal (COMB1 and COMB2; COMB2 $=\frac{1}{2} S C+O_{3}$ ). Observed changes are expressed as a sequence of 25 time-varying anomaly patterns (relative to the base period 1963-73), spanning the period 1963 to 1987 . Observed data were filtered to reduce high-frequency noise, as described in Fig. 1. For each season and model experiment, one pattern characterizes the model response to the imposed anthropogenic 
forcing. This fixed pattern is then correlated with the observed time-varying spatial patterns. Results are for temperature-change patterns defined over the full vertical extent of the Oort data ( 50 to $850 \mathrm{hPa}$; panel a) and over the mid- to lower troposphere only (500 to $850 \mathrm{hPa}$; panel b). Note that trends in $R(t)$ are relatively insensitive to the choice of averaging period for defining observed anomalies ${ }^{1}$.

Figure 4: Magnitude of linear trends in the $R(t)$ statistic in the absence of external forcing. 'Natural variability' $R(t)$ time series were computed by correlating the fixed pattern of annually-averaged vertical temperature changes in the SC experiment (Fig. 1c) with the time-varying temperature-change patterns from the 310- and 1,000-year Hadley Centre and GFDL control integrations. Model anomaly patterns were defined relative to the overall time-mean of each control run, and were filtered in the same way as the observations ${ }^{1}$. The figure shows the result of fitting running linear trends to 10-, 15- and 25-year segments of the unforced $R(t)$ time series, and then plotting the magnitude (at any point in time) of the linear trend in $R(t)$. This yields the distribution of all possible unforced $R(t)$ trends for the selected timescales. The horizontal dashed lines in each panel give the magnitude of the $R(t)$ trend for the comparison of the SC signal with observations over 1978-87, 1973-87, and 1963-87 (see Fig. 3a). The level of time-increasing similarity between the observed vertical temperature-change patterns and the $\mathrm{SC}$ signal over the last 25 years is highly unusual relative to the unforced 25-year $R(t)$ trends. In contrast, recent 10-year trends in $R(t)$ are not unusual occurrences. All results are for temperature-change patterns defined over 50 to $850 \mathrm{hPa}$. $R(t)$ trends are plotted on the central year of the trend; GFDL results are shown for the first 300 years only.

Table 1: Significance levels ( $p$-values) for seasonal- and annual vertical temperaturechange signals from the TP $\mathrm{C}$ and $\mathrm{SC}$ experiments and from the COMB1 and COMB2 sensitivity studies. The signals of interest are the linear trends for the most recent 10,15 , and 25 years of the $R(t)$ time series shown in Figs. $3 \mathrm{a}$ and b. - i.e., the trends over 1978-87, 1973-87, and 1963-87. These trends provide information on the degree of time-increasing pattern similarity between the observations and the model simula- 
tions. To determine whether natural internal variability could mimic the searched-for signal patterns, and produce $R(t)$ trends of equal or greater magnitude than the signal trends of interest, we correlated the seasonal and annual C, SC, COMB1 and COMB2 signals with temperature anomalies from 310- and 1,000-year CGCM control integrations, as described in Fig. 4. Significance levels were then computed by comparing the 'signal' $R(t)$ trends with the appropriate sampling distributions for unforced trends'. Shaded boxes denote results that achieve significance at the $5 \%$ level or better. In these cases, the time-increasing similarity between model signal patterns and observations is unlikely to be due to (model estimated) internally-generated natural variability. 
a) Taylor/Penner $\mathrm{CO}_{2}$-only Signal

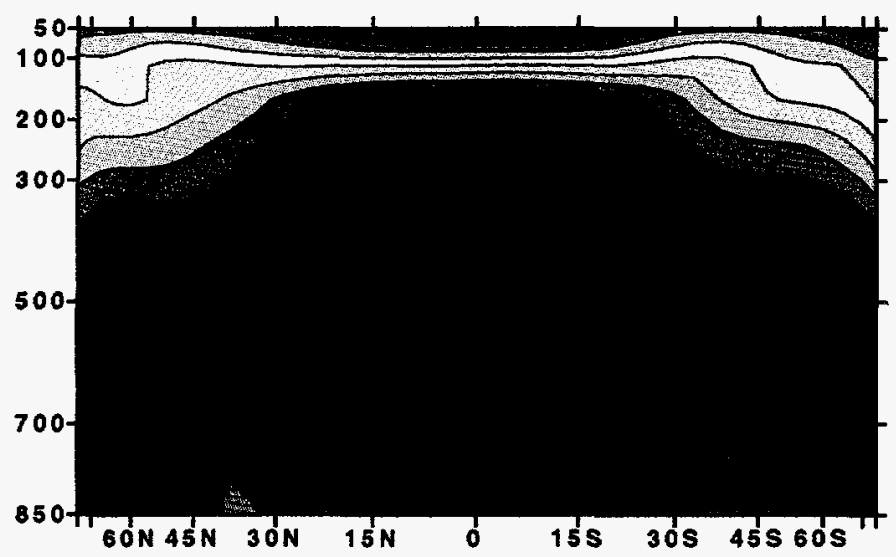

c) Taylor/Penner $\mathrm{CO}_{2}+\mathrm{SO}_{4}$ Signal

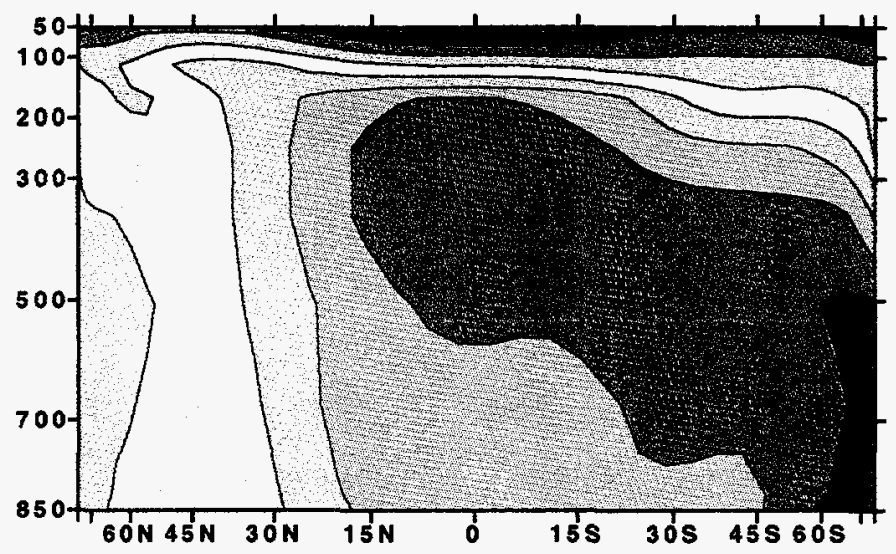

e) TP $\mathrm{CO}_{2}+\mathrm{SO}_{4}+$ Ramaswamy et al. $\mathrm{O}_{3}$ Signal

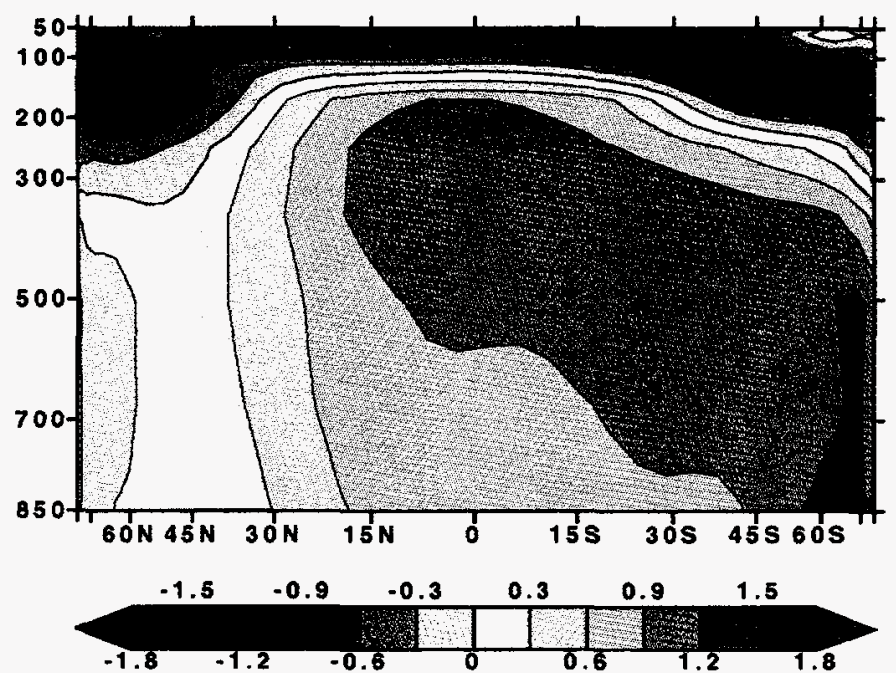

b) . Taylor/Penner $\mathrm{SO}_{4}$-only Signal

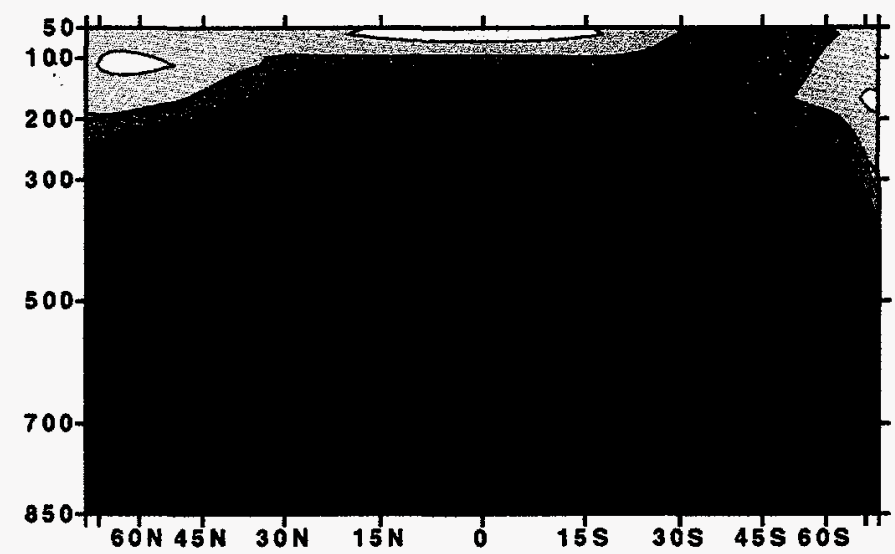

d) Ramaswamy et al. $O_{3}$-only Signal

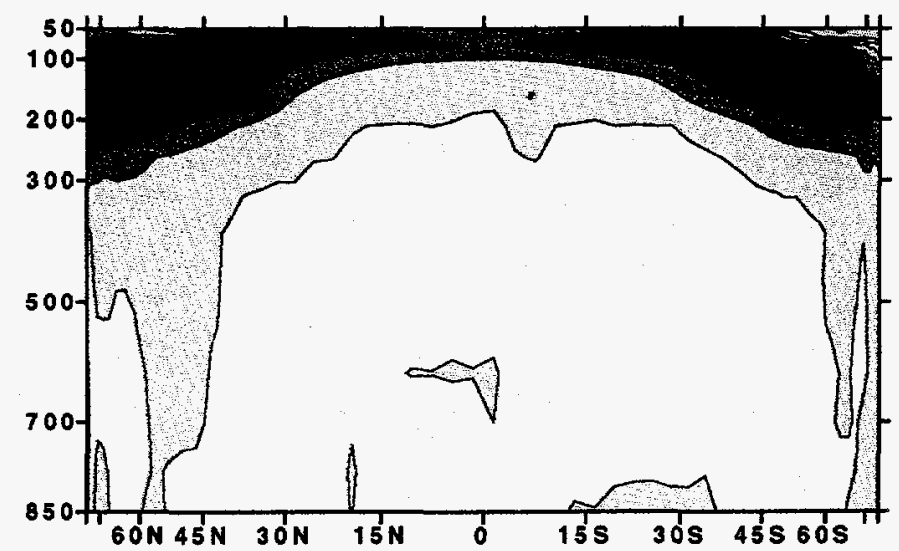

f) Oort Linear Trends over 1963-87

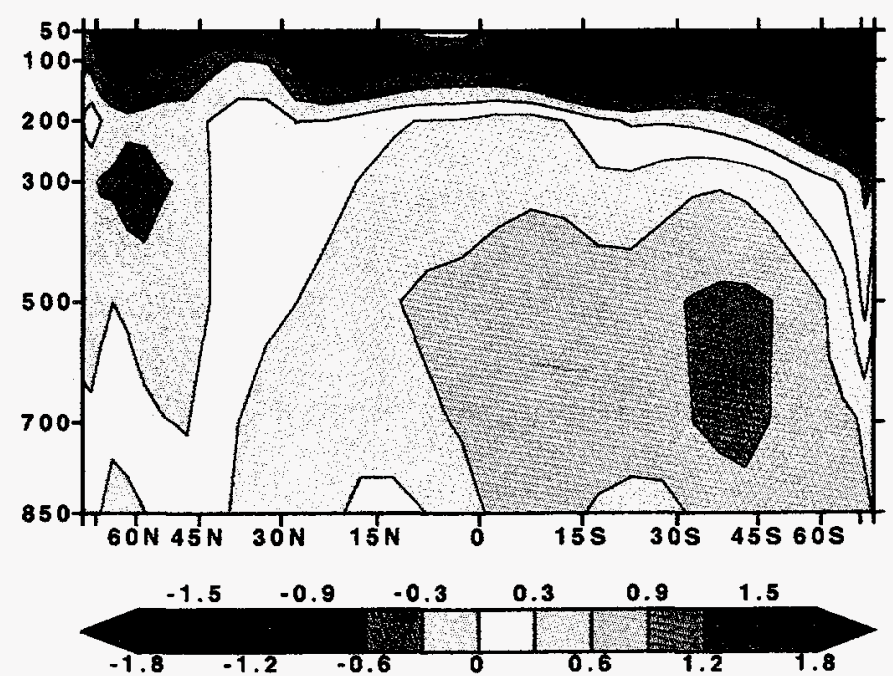

Units Model signals: Degrees C

Observations: Degrees C / 25 yrs

SANTER ET AL. FIG. 1 


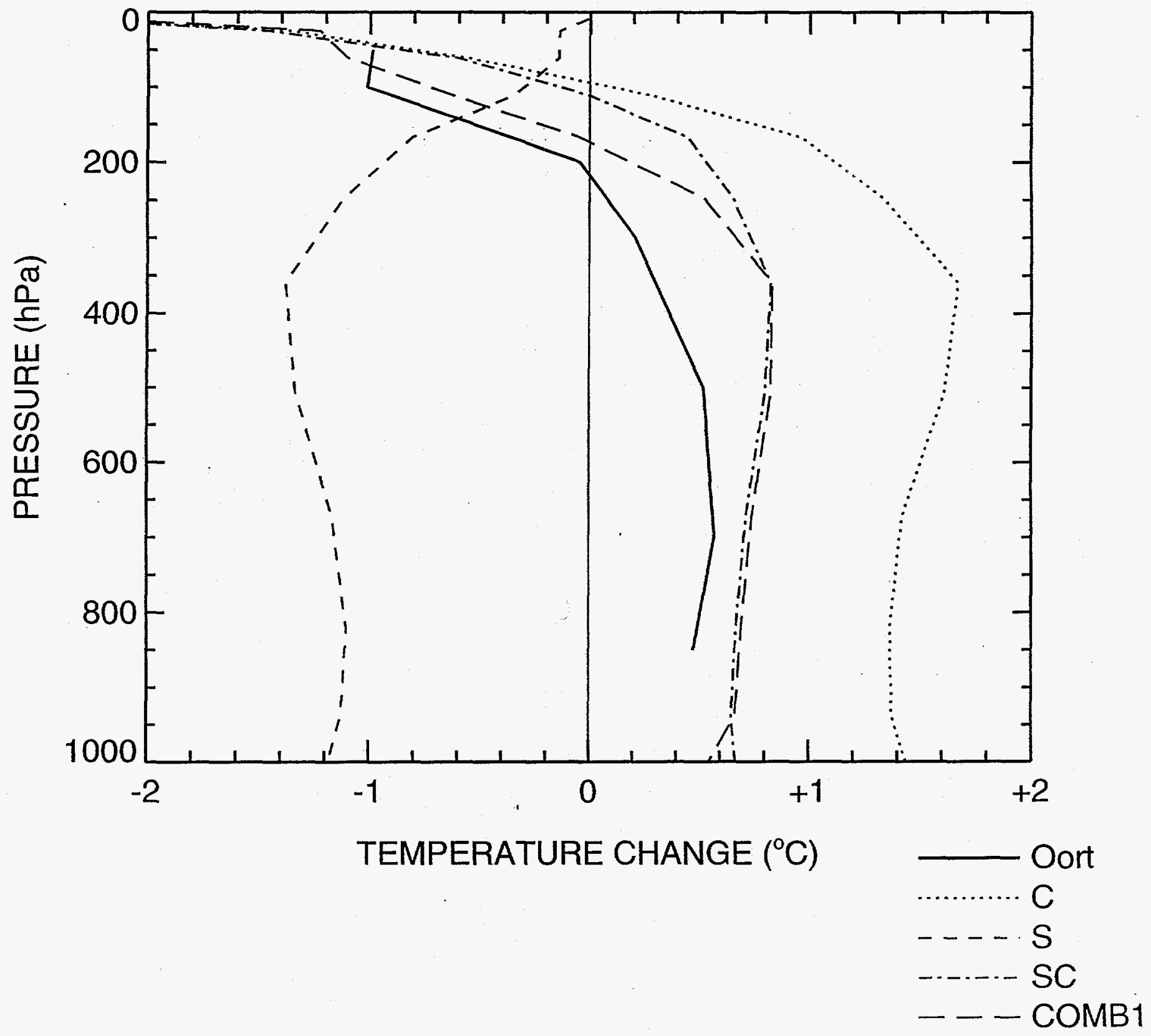

SANTER ET AL. FIG. 2 


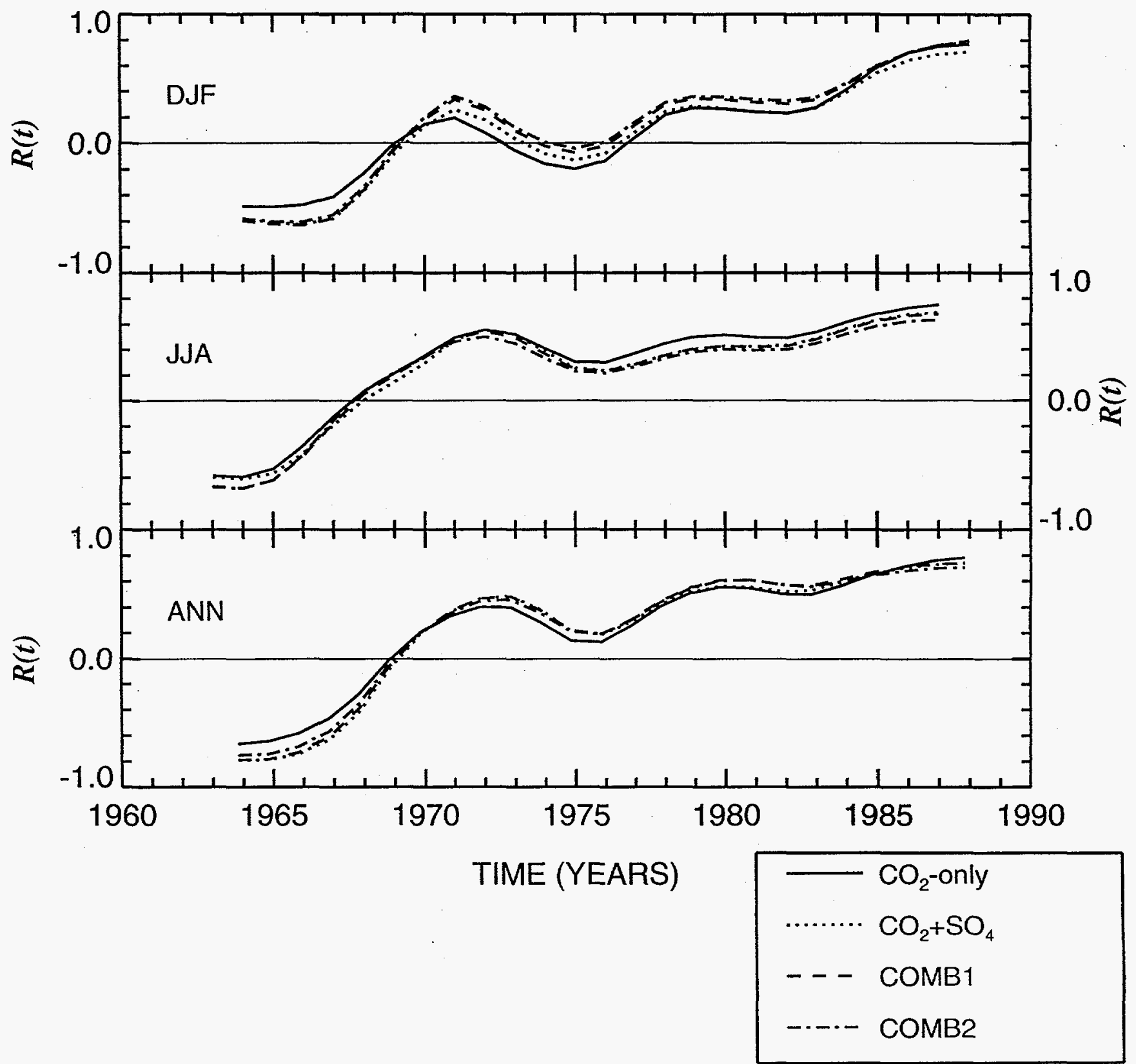

SANTER ET AL. FIG $3 a$ 


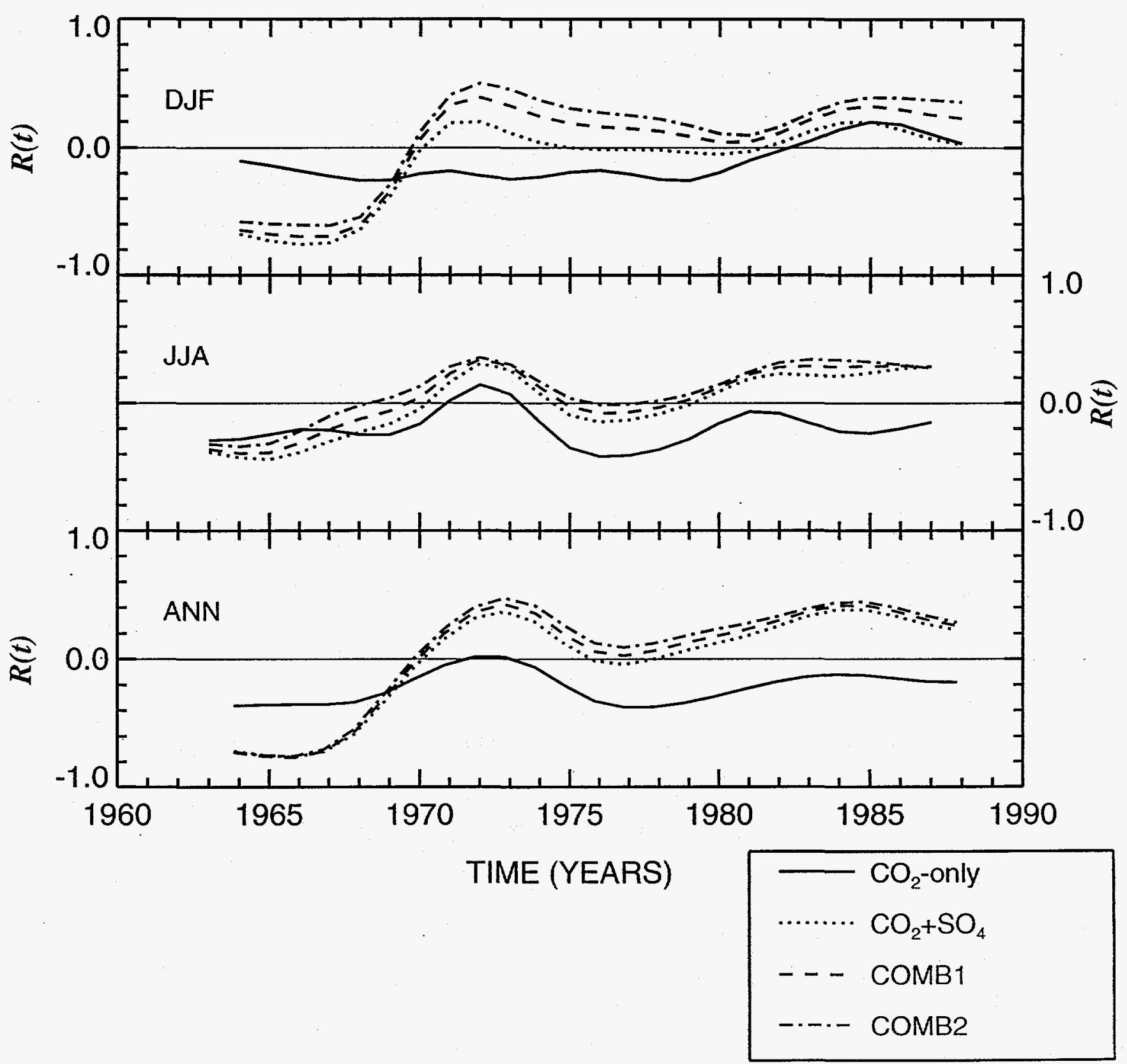




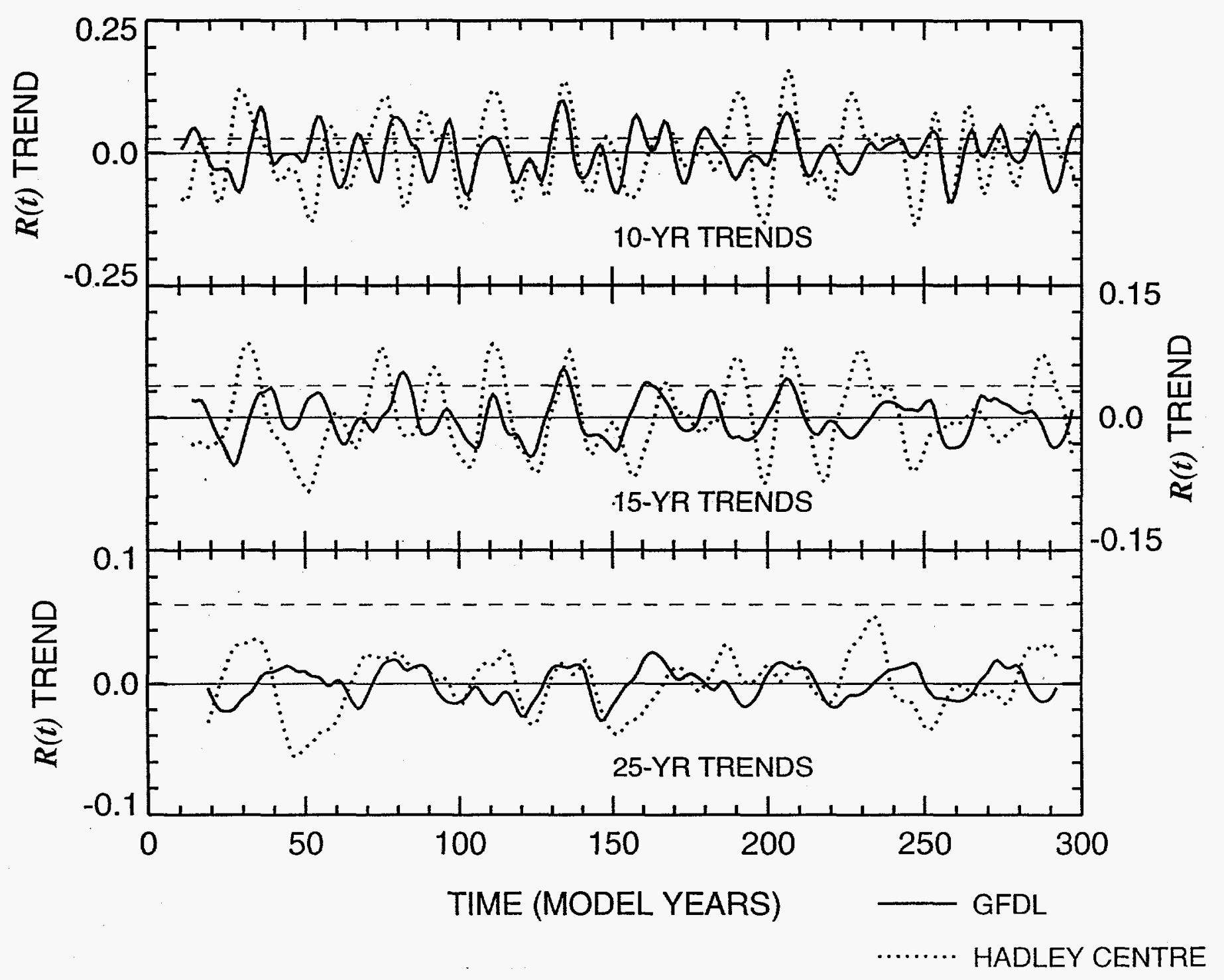




\begin{tabular}{|c|c|c|c|c|c|c|c|}
\hline & & \multicolumn{6}{|c|}{ TREND LENGTH (YEARS) } \\
\hline & & \multicolumn{2}{|c|}{10} & \multicolumn{2}{|c|}{15} & \multicolumn{2}{|c|}{25} \\
\hline & & $\begin{array}{c}50-850 \\
h P a\end{array}$ & $\begin{array}{c}500-850 \\
h P a\end{array}$ & $\begin{array}{c}50-850 \\
h P a\end{array}$ & $\begin{array}{c}500-850 \\
\mathrm{hPa}\end{array}$ & $\begin{array}{c}50-850 \\
h P a\end{array}$ & $\begin{array}{c}500-850 \\
h P a\end{array}$ \\
\hline SEASON & EXPT & & & & & & \\
\hline \multirow{4}{*}{$\begin{array}{l}D J F \\
(G F D L)\end{array}$} & $C$ & 10.00 & 0.18 & 0.01 & 0.12 & & 0.13 \\
\hline & & $-\sqrt{0.03}=$ & 0.37 & 1000 & 0.40 & & 0.0 \\
\hline & $C O M B 1$ & .0 .04 & 0.30 & $9.00=$ & 0.41 & 0.18 & 0.08 \\
\hline & COMB2 & 0.06 & 0.28 & 0.00 & 0.43 & & 0.02 \\
\hline \multirow{4}{*}{$\begin{array}{l}J J A \\
(G F D L)\end{array}$} & $C$ & 0.20 & 0.44 & 0.14 & 0.46 & .00 & 0.50 \\
\hline & $S C$ & 0.16 & 0.29 & 0.14 & 0.30 & 0.00 & 0.13 \\
\hline & $C O M B 1$ & 0.18 & 0.28 & 0.16 & 0.32 & 0.00 & 0.14 \\
\hline & $C O M B 2$ & 0.21 & 0.29 & 0.17 & 0.33 & 10.00 & 0.15 \\
\hline \multirow{4}{*}{$\begin{array}{l}A N N \\
(G F D L)\end{array}$} & $C$ & 0.22 & 0.38 & 0.03 & 0.39 & 1000 & 0.39 \\
\hline & $S C$ & 0.25 & 0.38 & 0.06 & 0.30 & 0.20 & \\
\hline & $C O M B I$ & 0.32 & 0.39 & 0.07 & 0.34 & 0.00 & 0.03 \\
\hline & COMB2 & 0.36 & 0.40 & 0.09 & 0.37 & 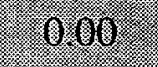 & \\
\hline \multirow{4}{*}{$\begin{array}{l}A N N \\
(U K M O)\end{array}$} & $C$ & 0.33 & 0.37 & 0.20 & 0.42 & 0100 & 0.43 \\
\hline & $S C$ & 0.35 & 0.35 & 0.23 & 0.29 & 0.00 & 0.00 \\
\hline & $C O M B I$ & 0.38 & 0.34 & 0.20 & 0.32 & 0.00 & 0.00 \\
\hline & $C O M B 2$ & 0.38 & 0.36 & 0.20 & 0.36 & 0.00 & 0.00 \\
\hline
\end{tabular}




\section{PCMDI REPORTS}

Number

1 The Validation of Atmospheric Model

2 Analysis of the Temporal Behavior of Tropical Convection in the ECMWF Model

3 The Effect of Horizontal Resolution of Ocean Surface Heat Fluxes in the ECMWF Model

4 Behavior of an Ocean General Circulation Model at Four Different Horizontal Resolutions

5. The Effects of Sampling Frequency on the Climate Statistics of the ECMWF General Circulation Model

6 Sensitivity of Dynamical Quantities to Horizontal Resolution in a Climate Simulation with the ECMWF Atmospheric General Circulation Model (Cycle 33)

7 AMIP: The Atmospheric Model Intercomparison Project

8 The Impact of Horizontal Resolution on Moist Processes in the ECMWF Model
Author(s)

$\underline{\text { Date }}$

W.L. Gates

March 1992

J.M. Slingo

April 1992

K.R. Sperber

J.-J. Morcrette

G.L. Potter

P.J. Gleckler

K.E. Taylor

C. Covey

August 1992

T.J. Phillips

W.L. Gates

K. Arpe

J.S. Boyle

October 1992

W.L. Gates

December 1992

T.J. Phillips

L.C. Corsetti

S.L. Grotch

September 1992

July 1992 
9 A Modeling Perspective on Cloud Radiative Forcing

10 The Use of General Circulation Models in Detecting Climate Change Induced by Greenhouse Gases

11 Preliminary Validation of the Low Frequency Variability of Tropospheric Temperature and Circulation Simulated for the AMIP by the ECMWF Model

12 Simulation of the Indian and EastAsian Summer Monsoon in the ECMWF Model: Sensitivity to Horizontal Resolution

13 Statistical Intercomparison of Global Climate Models: A Common Principal Component Approach

14 Ocean Variability and its Influence on the Detectability of Greenhouse Warming Signals
G.L. Potter

J.M. Slingo

J.-J. Morcrette

L. Corsetti

B.D. Santer

U. Cubasch

U. Mikolajewicz

G. Hegerl

J.S. Boyle

April 1993

K.R. Sperber

November 1993

S. Hameed

G.L. Potter

J.S. Boyle

S.K. Sengupta

November 1993

J.S. Boyle

B.D. Santer

January 1994

U. Mikolajewicz

W. Brüggemann

U. Cubasch

K. Hasselmann

H. Höck

E. Maier-Reimer

T.M.L. Wigley 
15 Cloud-Radiative Effects on Implied Oceanic Energy Transports as Simulated by Atmospheric General Circulation Models
16 DRS User's guide

17 The PCMDI Visualization and Computation System (VCS): A Workbench for Climate Data Display and Analysis

18 A Summary Documentation of the AMIP Models

19 Global Ocean Circulation and Equator-Pole Heat Transport as a Function of Ocean GCM Resolution

20 The Northern Wintertime Divergence Extreme at $200 \mathrm{hPa}$ and Surface Cyclones as Simulated in the AMIP Integration of the ECMWF General Circulation Model
P.J. Gleckler

March 1994

D.A. Randall

G. Boer

R. Colman

M. Dix

V. Galin

M. Helfand

J. Kiehl

A. Kitoh

W. Lau

X.-Z. Liang

V. Lykossov

B. McAvaney

K. Miyakoda

S. Planton

R. Drach

R. Mobley

March 1994

D.N. Williams

R.L. Mobley

T.J. Phillips

April 1994

C. Covey

June 1994

March 1994

November 1994 
21 Towards the Detection and

B.D. Santer

January 1995

Attribution of an Anthropogenic Effect on Climate

K.E. Taylor

T.M.L. Wigley

J.E. Penner

P.D. Jones

U. Cubasch

22 The Effect of Horizontal Resolution

G.L. Potter

July 1995 on Cloud Radiative Forcing in the ECMWF Model

23 Intercomparison of the Spectral Characteristics of $200 \mathrm{hPa}$ Kinetic Energy in Some AMIP Simulations

J.S. Boyle

August 1995

24 Documentation of the AMIP Models on the World Wide Web

T.J. Phillips

August 1995

25 Estimates of Zonally Averaged Tropical Diabatic Heating in AMIP GCM Simulations

26 Uncertainties in Global Ocean Surface

P.J. Gleckler

August 1995 Heat Flux Climatologies Derived B.C. Weaver

August 1995 from Ship Observations

August 1995 